\title{
Hannah Arendt, a psicanálise e a autoridade
}

Pedro Cattapan *

RESUMO: Este trabalho revisita o ensaio de Hannah Arendt 'O que é autoridade?', enfatizando o esforço da autora de restabelecer uma autoridade na modernidade calcada no Esclarecimento. Busca também relacioná-lo às reflexões freudianas acerca da autoridade e da educação, tentando mostrar aproximações e diferenças no pensamento dos dois autores sob o pano de fundo do perigo contemporâneo de uma reemergência do totalitarismo.

PALAVRAS-CHAVE: Hannah Arendt, autoridade, psicanálise, educação, totalitarismo.

ABSTRACT: This text revisits Hannah Arendt's essay 'What's authority?', emphasizing her effort to stablish onde more authority in modernity, this time based on Enlightment. The text tries too to link Arendt's thesis to Freud's reflexions on authority and education, aiming to show diferences and what seems to join their thoughts. This discussion gains strenght considering the danger of totalitarism in our time.

KEY-WORDS: Hannah Arendt, authority, psychoanalisis, education, totalitarism

RÉSUMÉ: Cette article revisite l'essai de Hannah Arendt "Qu'est-ce que l'autorité?", mettant l'accent sur les efforts de l'auteur pour rétablir une autorité modern basée sur les Lumières. Il cherche également corréler ce travail aux réflexions de Freud sur l'autotité et l'éducation, en essayant de montrer des approximations et des differences dans la pensée des deux auteurs dans le context du risque contemporain d'une reemergence du totalitarisme.

MOTS CLÉS: Hannah Arendt, psychanalyse, éducation, totalitarisme.

* Pós-Doutor em Teoria Psicanalítica pelo IP-UFRJ, Doutor em Saúde Coletiva pelo IMS-UERJ, professor associado do IHSUFF, pedrocattapan@hotmail.com 


\section{Vivemos uma nova ascensão do totalitarismo?}

Coincidência ou não, os organizadores do evento que propiciou a escrita deste trabalho entenderam ser importante refletirmos sobre a autoridade na atualidade. A filósofa Hannah Arendt, quando escreveu seu célebre ensaio "O que é autoridade?", de 1954, explicou que tal trabalho foi inspirado pela realidade do totalitarismo, que na perspectiva dela, deveria ser pensado como uma resposta, um sintoma da perda de autoridade política.

Por isso mesmo, entendo que talvez seja de grande valia para este colóquio, retomar as reflexões de Arendt sobre a autoridade política e articulá-las com algumas reflexões de Freud sobre o mesmo assunto. A psicanálise também se desenvolveu ao longo do século XX e início do XXI como uma perspectiva teórico-clínica crítica e interessada no tema da queda da autoridade. Acredito que cotejar o pensamento de Freud com o de Arendt pode ser de grande valia para ambos e para nossa realidade contemporânea, se é verdade que vivemos uma crise da autoridade.

\section{O que é autoridade?}

No seu artigo já citado, Arendt busca demarcar uma diferença entre autoridade e poder: a autoridade se explicitaria na obediência enquanto o poder se exerceria através da violência. Onde ocorre o uso da força, poderíamos dizer que a autoridade fracassou.

O adjetivo 'autoritário' no texto da autora não significa um abuso de poder, mas apenas o que se refere à autoridade. É nesse sentido que ela nos propõe que a ordem autoritária - onde a autoridade vigora - é sempre hierárquica, piramidal. O que dá lógica a esta ordem não é nem a razão, nem a força bruta, mas o passado; é ligada historicamente à religião e/ou à tradição. O governo autoritário se baseia numa autoridade superior a ele próprio, mais antiga.

Se é assim, a desconstrução iluminista da autoridade da tradição e da religião, bem como a constatação de Nietzsche de que Deus está morto (NIETZSCHE, 2008) marcam a perda da fé e da religião, por um lado - aliás, a dúvida moderna, já detectada em Pascal (PASCAL, 2004) e Descartes (DESCARTES, 2006), pode ser tomada como um início desta morte - e, por outro, da tradição, que se percebe na intencional operação moderna de ruptura, de perda da continuidade, do fio condutor que liga vidas através dos tempos - Arendt enxerga aí o risco de perda da memória e seu correlato psíquico: a profundidade. Por isso, um dos medos do homem moderno é o da impermanência, da insegurança e desamparo no mundo.

Outra evidência da relação com o poder entre modernidade e era pré-moderna está em que a modernidade estaria marcada bem mais pelas práticas de persuasão - que supõem igualdade - e pela 
ameaça (às vezes concretizada) do totalitarismo - que supõe a dominação violenta - do que pela obediência à autoridade, própria do mundo pré-moderno. A queda da autoridade define a modernidade.

Se o desgaste do passado contribuiu para a crise da autoridade, a derrocada da liberdade, patente na lógica totalitária do século XX, também contribuiu. O totalitarismo, para Arendt, funcionaria numa lógica diferente da temporalidade da modernidade tomada como um movimento para frente. A noção de história como linearidade é anulada; seja a linha decendente da 'decadência da autoridade', perspectiva conservadora, seja a linha ascendente do 'progresso da liberdade' liberal. No totalitarismo ocorre uma estagnação do tempo e uma espacialização da dominação onde cada estrato social serve de realidade para um e continuidade do poder violento sobre outro; o líder está dentro do movimento totalitário, e não acima, como autoridade. O totalitarismo é o fim da autoridade e da liberdade ao mesmo tempo (ARENDT, 2009).

Portanto, se não faz sentido tratarmos de autoridade nos regimes modernos da persuasão ou totalitário/violência, é preciso, argumenta Arendt, voltarmos ao passado para compreendermos o que quis dizer o termo autoridade.

Autoridade é uma palavra e um conceito romanos, não existentes na Grécia antiga. Se alguns enxergaram nas obras de Platão e Aristóteles referências à autoridade, para Arendt, trata-se de má interpretação daqueles textos. Os dois filósofos gregos mencionados buscaram na administração doméstica instrumentos para forjar e pensar uma autoridade política exatamente porque tal autoridade não existia na pólis grega. Platão tenta equacionar o senhor (o déspota) com a autoridade enquanto Aristóteles tenta equacioná-la com o especialista (seja o mais velho/educador na relação com o jovem/aluno, seja o médico com seu paciente); operações que tiveram efeito prolongado no pensamento e práticas ocidentais e, a rigor, duram até hoje.

Arendt indica os problemas destas operações: o âmbito político é o âmbito dos adultos, para adentrá-lo é esperado que, justamente, o processo de educação tenha terminado. A criança e o adolescente estão retirados do âmbito político como sujeitos pois ainda estão no âmbito da educação. Arendt compreende a educação como capacitação à participação nos problemas públicos; portanto, a educação completa torna alguém apto a se colocar como sujeito político, no âmbito político. O horror moderno à autoridade aparece com bastante destaque no século XX como horror à autoridade escolar, o que deixa claro tanto a herança duradoura da mistura aristotélica de autoridade com educador, como a perda moderna do conceito de autoridade. A autoridade escolar é, originalmente, irrelevante em termos políticos. Tornar cada posição de autoridade num educador, num senhor e/ou num médico dos subordinados é apenas uma estratégia de dominação, de busca de garantias para o exercício do poder num contexto em que a autoridade rateia. 
Só há uma única situação em que a autoridade pública e a educação convergem, e não é a nossa, moderna. Tratar-se-ia do modelo romano antigo. Naquela sociedade, a autoridade era a virtude dos antepassados: A verdade e o bem estavam nas origens e caberia a cada nova geração mapear e interpretar a existência contemporânea à luz dos exemplos e sabedoria dos antepassados, caberia aos mais novos tentar estar à altura dos antigos. O antepassado é maior, tem grandeza em relação ao atual. Por isso mesmo, foram os próprios romanos que transmutaram Platão e Aristóteles de utópicos em clássicos, referências a serem imitadas: autoridades.

Na civilização romana, uma vez que algo era criado, deveria ser preservado. Caberia às gerações futuras preservar e conservar o que foi criado: antes de tudo, a própria fundação de Roma é o maior exemplo disso; há algo de sagrado neste ato. A religião dos romanos, dessa feita, se assemelha à tradição, à atividade política e à educação romanas: todas relacionam-se com o passado, com a Auctoritas, característica dos anciãos, do Senado, dos Patres, que a recebiam da tradição, dos antepassados.

E vê-se, então, a distinção inicial do trabalho de Arendt entre autoridade e poder na máxima de Cícero: O poder reside no povo, a autoridade no Senado (CÍCERO, 1968). A autoridade não ordena, faz referência aos exemplos passados, se refere aos mapeamentos e às tradições, mas a decisão e a ação são do povo...e, mais tarde, do Imperador... Assim, admite Arendt, autoridade não é algo tão fácil de definir; é mais que conselho, porém menos que ordem; um conselho que não se pode ignorar sem risco. A autoridade aprova ou desaprova, mas não proíbe ou obriga; há alguma gravidade, alguma coerção na autoridade, mas nada além disso.

A voz dos antepassados tem peso, mas não é uma lei. Como se pode perceber, a estrutura piramidal da autoridade romana é diferente de nossa pirâmide social da sociedade disciplinar moderna (FOUCAULT, 2013). A pirâmide romana tem seu vértice invertido, a parte debaixo da pirâmide diria respeito aos antepassados, à tradição - onde estaria a autoridade. Quando o Império se cristianizou, a Igreja herdou este conceito de autoridade, porém ao substituir a fundação de Roma pelo advento do Cristo, a pirâmide se inverteu para o formato que conhecemos hoje: o ponto superior da pirâmide é ocupado por Cristo que é tradição, que é passado, mas é também, pela sua transcendência, presente, Deus.

Ainda assim, na Idade Média, a partição romana se manteve. De um lado, a autoridade da Igreja, de outro, o poder do príncipe. No entanto, esta partição retira a autoridade do campo político, diferente da ordem social romana. A partir daí, a autoridade passou a ser atributo cada vez mais exclusivo da religião e suas duas subalternas - a filosofia e a teologia -, enquanto o poder político do príncipe arriscou-se a não ter autoridade. Reconhecendo o perigo do exercício do poder sem autoridade (a insubordinação), buscou se ligar à autoridade/religião através do direito divino. Religião, filosofia e teologia, com o tempo, 
terminam por impor seus padrões transcendentais judicativos da realidade para o campo da política forçando assim referências político-morais gerais, ideais a se alcançar, cuja referência última é o Cristo.

As coisas teriam permanecido assim caso uma tática de dominação empregada por séculos pela Igreja não tivesse minado a autoridade romano-cristã de vez: a invenção e o uso da noção de Inferno. Sabemos que o Inferno foi utilizado como instrumento de persuasão (origem do modo moderno de exercício do poder) e violência (origem do modo totalitário de dominação). Com o advento do Inferno, o respeito ao clero se deveu desde então mais ao sermão, à capacidade de argumentação, ou à ameaça da violência do Inferno do que à autoridade. Talvez possamos dizer que o respeito foi se transformando ou em temor ou em reconhecimento de saber.

No entanto, a civilização moderna - dos séculos XVIII, XIX e XX - fez o Inferno quase desaparecer da discursividade da Igreja e dos fiéis. O fim do temor do Inferno que caracteriza o mundo moderno não invalida a derrocada da autoridade, perdida na história. Ao contrário, seria a marca de um distanciamento a mais em relação à autoridade: a vítima morreu, e seu assassino também, de modo que não há mais acesso direto àquela.

$\mathrm{Na}$ modernidade não se percebe mais a diferença entre autoridade, violência e persuasão, em detrimento da primeira. Os revolucionários ainda almejam adaptar o real à referência transcendente mas não hesitam diante da violência. Perdeu-se a autoridade romana, mas não o artifício aristotélico de buscar no político, no médico, no perito, no piloto, no educador uma referência de autoridade; figuras persuasivas por uma posição hierárquica na relação social devido à detenção de um saber, que, em nome do mesmo, em situações extremas, podem fazer uso da violência - como Foucault bem mostrou em suas análises dos especialistas, figuras tão importantes da pirâmide social disciplinar e biopolítica (FOUCAULT, 2002).

Arendt termina seu ensaio acreditando que se tomarmos a Revolução Moderna (seja a Francesa, seja a Americana) como ato de fundação e o próprio projeto iluminista como nossa 'nova tradição', teremos todos os instrumentos para reconhecer autoridade na produção de saber e crítica das luzes e não em quem defende o argumento, na esteira de Kant em seu célebre artigo sobre o que é o Esclarecimento (KANT, 2016), menos ainda em seu poder persuasivo ou no uso da violência.

\section{Freud, autoridade e educação}

Pois bem, terminada nossa apreciação do pensamento de Hannah Arendt sobre o tema da autoridade, passaremos agora a Freud e algumas de suas reflexões sobre os temas articulados ou não da autoridade e da educação. 
Mesmo tendo se tornado famoso por suas críticas veementes à tentação educativa de alguns jovens analistas (FREUD, 1996/1912e), como os profissionais da educação costumam saber, Freud, em algumas ocasiões, chamou a própria psicanálise de uma segunda educação ou de uma pós-educação (FREUD, 1996/1913j, 1916d, 1916-1917 [1915-1917], 1933a [1932]) - o que aliás alimentou muitas polêmicas, críticas, e más compreensões. Acho que seria no mínimo interessante começarmos nossa abordagem justamente a partir deste ponto. E é o que farei.

Em alguns textos como, por exemplo, "Moral sexual 'civilizada' e doença nervosa moderna" (FREUD, 1996/1908d), “O interesse científico da psicanálise” (FREUD, 1996/1913j) e, novamente, com ainda maior vigor em O mal-estar na civilização (FREUD, 1996/1930a [1929]), o psicanalista se posiciona claramente a respeito da pedagogia e dos processos de formação, enfim, da educação formal e familiar de sua época. A condena por um moralismo normalizador, cheio de hipocrisias a respeito da vida sexual, de forma que transmite desconhecimento e é força importante nos processos de recalcamento bem como de tornar crianças e adolescentes despreparados para lidar com a pulsão sexual e com a pulsão destrutiva do outro humano. Ao invés de falar francamente a respeito da sexualidade humana, do manejo da pulsão sexual e da crueldade, tais práticas - em parte por conta do pudor religioso - forçariam evitações e silêncios por parte dos adultos diante das questões sexuais das crianças e da violência contra elas, o que as tardaria numa posição de expectativa da revelação de um segredo e de um suposto know-how adulto idealizado sobre a lida com a sexualidade e a agressividade humana até estarem crescidos e, para muitos, mesmo depois.

É na esteira desta argumentação que é preciso compreender a sugestão de Freud de que se pense a psicanálise como uma pós-educação. Para ele, no tratamento psicanalítico, o que se realizaria seria um processo que, apesar de não ter este efeito como objetivo, sempre vem acompanhado dele: a franqueza com que psicanalista e psicanalisando tratam das questões difíceis da vida moral normalizada - morte, dinheiro e sexualidade, por exemplo -, e a própria atividade de associação livre propiciam ao paciente a possibilidade de desfazer certos recalcamentos, de elaborar e dar destinos a sua sexualidade e de admitir sua castração, sua dificuldade de domínio sobre o gozo; isto porque o processo analítico desmonta, aos poucos, a expectativa do neurótico de que um outro domina o campo sexual, um outro sabe como viver de modo a garantir o gozo e evitar o sofrimento e o desamparo diante da pulsão.

Ora, em outros termos, o que se passaria no processo analítico seria o descolamento do paciente de uma posição de dependência e submissão ao outro supostamente maduro, dotado de uma sexualidade exclusivamente adulta, senhor do gozo, para ganhar liberdade na afirmação de seu desejo e de seu modo/estilo de experimentar e lidar com a pulsão.

O ganho em liberdade viria conjugado a uma destruição da autoridade? Guardemos uma possível resposta a esta pergunta para depois de termos nos debruçado sobre o famoso mito freudiano da horda 
primeva, apresentado em Totem e tabu (FREUD, 1996/1912-1913) e retomado em Psicologia das massas e análise do eu (FREUD, 1996/1921c) e Moisés e o monoteísmo (FREUD, 1996/1939a [1937-1939]). Pretendo ser sucinto quanto ao mito, mas como não tenho certeza se todos os leitores já o conhecem, terei de descrevê-lo mantendo alguns detalhes importantes.

Freud supõe um momento primitivo, mítico, em que a humanidade se organizava em hordas compostas por um macho forte e brutal que possuía todas as fêmeas, pai de toda a prole e que proibia o uso das fêmeas pelos outros machos para seu gozo sexual e reprodução. Esta situação tornava todas as fêmeas esposas do macho-pai e todos os outros machos seus filhos e filhos-irmãos de algumas fêmeas. Tudo isso só teria mudado, desenvolve Freud, quando os filhos se uniram para assassinar o pai; além de cometer parricídio, em seguida os assassinos teriam devorado o cadáver em um banquete grupal. A absorção de parte do pai teria feito com que cada filho se identificasse com ele, guardasse-o em sua memória e conduta com o amor que também sentiam pelo progenitor. Dentre outros efeitos dessa assimilação do pai violento e feroz constaria o sentimento de culpa em cada indivíduo, calcado no respeito à lei do pai: daí em diante nasceriam os interditos do gozo com a mulher do pai (ou seja, a mãe e as irmãs), do parricídio e também, mas com menor importância na trama de ideias proposta por Freud, da antropofagia (como sabemos, o canibalismo continuou como prática aceita em diversas culturas; não se trata de um interdito tão generalizado como os outros dois). Deste modo, haveria uma teoria freudiana da autoridade calcada num passado que insiste compulsivamente e no qual cada ser humano encontra ou esconde uma verdade sobre si. Uma autoridade modelada sobre um mito fundador, onde profano e sagrado se misturam e se mantêm como mistério originário de uma tradição seguida até hoje. A autoridade pensada por Freud é de fato a autoridade no sentido de Arendt e se parece bastante com o modelo romano.

Sabe-se que quando Freud propôs este mito, o que ele buscou foi encontrar o Complexo de Édipo na origem e no âmago do Inconsciente de cada humano e, assim, da cultura como um todo. Muitas críticas já foram feitas a esta operação, obras inteiras como $O$ anti-Édipo: capitalismo e esquizofrenia de Gilles Deleuze e Félix Gattari (DELEUZE \& GUATARRI, 2010) se dedicam a isso. Tendo a concordar com o argumento principal destas críticas: tornar tudo explicado pelo Édipo reduz a possibilidade de se perceber e pensar outras fantasias, outras experiências, outros trilhamentos pulsionais que apontariam para destinos muito distantes da prisão edípica e cria o risco de o analista se tornar um novo moralista normalizador - o contrário do que Freud entendeu por pós-educação através da psicanálise.

Então, como articular a concepção da psicanálise como pós-educação e a mitologia de Totem e tabu de modo não contraditório?

Essa articulação é possível, dependendo da ênfase que é dada a partes diferentes de Totem e tabu. Afinal, no desenvolvimento de seu mito edípico fundador, Freud nos conta que esta experiência determinante do interdito do incesto e do parricídio serviu de modelo para que nossa cultura pudesse 
construir outras instituições sociais como a religião, o Estado e o campo jurídico e seria ingrediente fundamental na projeção de autoridade no professor, no médico, no político etc. Tratar-se-ia de uma transferência paterna para outras figuras de modo a manter as fantasias que se realizam com a imago paterna possíveis de continuar a satisfazer desejos mesmo na relação com outrem. Enfim, é disto mesmo que se trata quando se aborda o conceito psicanalítico de transferência, como trabalhado em "A dinâmica da transferência" (FREUD, 1996/1912b) e "Recordar, repetir e elaborar (Novas recomendações sobre a técnica da psicanálise II)" (FREUD, 1996/1914g) a respeito da experiência clínica.

Pois bem, como Freud nos mostra em seus artigos sobre a técnica analítica e, novamente ao final de sua obra e vida, em “Análise terminável e interminável” (FREUD, 1996/1937c) (o que reforça a manutenção de uma posição ao longo da evolução de seu pensamento), numa psicanálise, a transferência pode funcionar como resistência à própria análise e caberia ao processo analítico desmontar a crença de que há um outro - pai ou substituto do pai - que protegeria o sujeito de todo desamparo diante das pulsões e do mundo e, por consequência, o submeteria à sua vontade. Uma psicanálise rumaria para o que Freud chama de matar opai, para, com isso autorizar o sujeito a cuidar de si. Mas como Lacan retificou, matar o pai, prescindir dele, porém na condição de nos servirmos dele (LACAN, 2005): o pai deixa de ser poder violento, força, obrigação e se tornaria de fato Auctoritas, como Arendt defende, em suma, uma referência, um mapeamento, um tesouro de exemplos, mas que não exigem submissão. Não seria isso que, através de outra articulação, Michel Foucault acreditou encontrar no que chamou de Idade de Ouro do cuidado de si? Foucault viu prosperar na Roma Imperial uma cultura em que o poder não exige submissão, assujeitamento, mas, de modo diferente, se apresenta como ofertas de possibilidades de bemviver, como normas concorrentes que seriam apropriadas pelos sujeitos de modo ético; o sujeito participaria da decisão e construção de sua relação com a norma e não se colocaria como vassalo dela (FOUCAULT, 2004).

Ora, só então, a autoridade descrita por Arendt como perdida, poderia encontrar espaço na psique moderna, como referência mantida após o sujeito ter abraçado a prática crítica de si e da cultura própria da psicanálise e herdeira da Aufklarung e que Foucault quis resgatar também da Roma Antiga. Liberdade e autoridade não seriam opostas nestas condições. Não é por acaso que é justamente neste momento de sua obra que Foucault se coloca dentro da linhagem crítica kantiana (FOUCAULT, 2000), voltando-se ao mesmo artigo kantiano que reconhecemos basal para a concepção arendtiana de que a autoridade poderia ser reeditada caso tomássemos o advento da crítica iluminista como marco fundador e momento a ser reimpresso insistentemente na sociedade moderna.

Decorre destas reflexões também que o modelo de cultura como repetição do Édipo (cuja autoridade é um herdeiro do tirano da horda, de certo modo afetada pelo modelo platônico) e, mais micropoliticamente, a expectativa de encontrar autoridade nos especialistas - seja o analista, o professor, o político - como representações do pai (modelo aristotélico) não serviriam para se desenvolver a 
liberdade do sujeito nem uma autoridade nos moldes descritos por Arendt. Seriam, ao contrário, sintomas da modernidade, onde a autoridade se ausenta e, em seu lugar buscou-se o saber dos especialistas ou o poder violento da força.

\section{Conclusão}

O que a tradição crítica das Luzes - que Arendt vê como uma possível reemergência da autoridade - é, não pode ser compreendida nem como uma submissão ao saber dos especialistas, nem uma submissão à violência totalitária. A psicanálise, como filha tardia da crítica, sempre corre o risco de ser uma reprodução de saber do especialista ou dominação feroz sobre o sujeito desamparado, mas assim procedendo estaria longe do que Freud concebeu e praticou como tratamento psicanalítico e que é reeditado por inúmeros psicanalistas no mundo. A psicanálise, se praticada como um trabalho assistido pelo psicanalista de o sujeito tomar posse de seu desejo e de suas modalidades de encontrar prazer, necessariamente age como herdeira de um procedimento crítico sobre si e o mundo, permitindo um descolamento de uma moral normalizadora e opressiva, tornando o sujeito autor de sua história e, portanto, mais livre do que no momento em que entrou no tratamento. Além disso, a autoridade terá sobrado para ele como referência e não mais como força punitiva, humilhante.

Bem, considerando tudo o que foi dito até agora, devemos compreender a famosa autoridade decadente do professor como uma autoridade em decadência desde há muito tempo, e o que o mantém como figura de respeito escora-se bem mais em seu poder argumentativo, em seu saber de especialista, em seu poder quiçá intimidante e violento de adulto diante de criança, de uma projeção da autoridade parental em alguém que não é o pai da criança. Segundo a proposta de Arendt por um lado e, por outro, as reflexões de Freud sobre a autoridade que resta ao final de uma travessia psicanalítica, podemos defender que a autoridade em que é possível o processo educacional se conectar e que pode encontrar bases mais sólidas não está na nostalgia de um poder paterno decaído, não está também no especialista que sabe mais (afinal se seu saber pareceu iludir alguns de que havia domínio e totalidade, desde os tempos de Google não ilude mais ninguém).

A autoridade em que a educação se baseia, a partir do que demonstrei aqui, poderia ser aquela mesma que tornou a educação objeto de preocupação política no final do século XVIII. As Luzes e a crítica calcada na razão perceberam na educação um instrumento necessário contra tradições infernais e servidões voluntárias e involuntárias ao poder e ao saber dominantes. A educação deveria capacitar os modernos a fazer avançar o projeto crítico das Luzes; sabemos que a invenção da escola moderna teve por efeito fazer avançar o saber das Luzes, a submissão aos especialistas, mas não a capacidade crítica. Está na afirmação da crítica como nossa tradição que nós, professores e intelectuais, encontraremos autoridade não na pessoa do professor, mas naquela atividade que transmite ao mesmo tempo liberdade, autoridade 
e confere ao seu praticante o que podemos chamar de autoria, ou, psicanaliticamente falando, afirmação de seu desejo: a crítica.

\section{REFERÊNCIAS}

ARENDT, Hannah. "O que é autoridade?” in. . Entre o passado e o futuro. São Paulo: Perspectiva, 1979.

. Origens do totalitarismo: antissemitismo, imperialismo, totalitarismo. São Paulo: Companhia das letras, 2009.

CÍCERO, Marcus Tullius. Traité des Lois. Paris: Les belles Lettres, 1968.

DELEUZE, Gilles; GUATARRI, Félix O anti-Édipo: capitalismo e esquizofrenia. São Paulo: 34, 2010.

DESCARTES, René. Discurso do método, Regras para a direção do espírito. São Paulo: Martin Claret, 2006.

FOUCAULT, Michel. “O que são as Luzes?” in. . Ditos e escritos II: arqueologia das ciências e história dos sistemas de pensamento. Rio de Janeiro: Forense universitária, 2000.

. Os anormais: curso no Collège de France (1974-1975). São Paulo: Martins Fontes, 2002.

. A bermenêtitica do sujeito: curso no Collège de France (1981-1982). São Paulo, Martins Fontes, 2004

. Vigiar e punir: nascimento da prisão. Petrópolis: Vozes, 2013.

FREUD, Sigmund. Edição standard brasileira das obras psicológicas completas de Sigmund Freud, Rio de Janeiro: Imago, 1996.

(1908d) "Moral sexual 'civilizada' e doença nervosa moderna”, v. IX

(1912b) “A dinâmica da transferência”, v. XII

(1912e) "Recomendações aos médicos que exercem a psicanálise”, v. XII

(1912-1913) Totem e tabu, v. XIII

(1913j) “O interesse científico da psicanálise”, v. XIII

(1914g) "Recordar, repetir e elaborar (Novas recomendações sobre a técnica da psicanálise II)”, v. XII

(1916d) “Alguns tipos de caráter encontrados no trabalho psicanalítico”, v. XIV

(1916-1917 [1915-1917) Conferências introdutórias sobre a psicanálise, vs. XV-XVI

(1921c) Psicologia de grupo e análise do ego, v. XVIII 
(1930a [1929]) O mal-estar na civilização, v.XXI

(1933a [1932]) Novas conferências introdutórias sobre psicanálise, v. XXII

(1937c) “Análise terminável e interminável”, v.XXIII

(1939a [1937-1939]) Moisés e o monoteísmo, v.XXIII

KANT. Immanuel. O que é Esclarecimento? Rio de Janeiro: Via Verita, 2016.

LACAN, Jacques. O seminário livro XXIII: o sinthoma. Rio de Janeiro: Jorge Zahar, 2005.

NIETZSCHE, Friedrich. A gaia ciência: la gaya scienza. São Paulo: Escala, 2008.

PASCAL, Blaise. Pensamentos. São Paulo: Martin Claret, 2004. 